\title{
Clinical Study \\ High-Intensity Interval Training in Patients with Substance Use Disorder
}

\author{
Grete Flemmen, ${ }^{1,2}$ Runar Unhjem, ${ }^{1}$ and Eivind Wang ${ }^{1}$ \\ ${ }^{1}$ Department of Circulation and Medical Imaging, Faculty of Medicine, The Norwegian University of Science and Technology, \\ 7006 Trondheim, Norway \\ ${ }^{2}$ Department of Research and Development, Clinic of Substance Use and Addiction Medicine, St.Olav's University Hospital, \\ 7030 Trondheim, Norway
}

Correspondence should be addressed to Grete Flemmen; grete.flemmen@ntnu.no

Received 21 December 2013; Revised 22 January 2014; Accepted 23 January 2014; Published 2 March 2014

Academic Editor: Lars L. Andersen

Copyright (C) 2014 Grete Flemmen et al. This is an open access article distributed under the Creative Commons Attribution License, which permits unrestricted use, distribution, and reproduction in any medium, provided the original work is properly cited.

\begin{abstract}
Patients with substance use disorder (SUD) suffer a higher risk of cardiovascular disease and other lifestyle diseases compared to the general population. High intensity training has been shown to effectively reduce this risk, and therefore we aimed to examine the feasibility and effect of such training in SUD patients in clinical treatment in the present study. 17 males and $7 \mathrm{females}$ ( $32 \pm 8 \mathrm{yr}$ ) in treatment were randomized to either a training group (TG), treadmill interval training in $4 \times 4$ minutes at 90-95\% of maximal heart rate, 3 days a week for 8 weeks, or a conventional rehabilitation control group (CG). Baseline values for both groups combined at inclusion were $44 \pm 8$ (males) and $34 \pm 9$ (females) $\mathrm{mL} \cdot \mathrm{min}^{-1} \cdot \mathrm{kg}^{-1}$, respectively. $9 / 12$ and 7/12 patients completed the TG and $\mathrm{CG}$, respectively. Only the TG significantly improved $(15 \pm 7 \%)$ their maximal oxygen consumption $\left(\mathrm{VO}_{2 \max }\right)$, from $42.3 \pm 7.2 \mathrm{~mL}$. $\mathrm{min}^{-1} \cdot \mathrm{kg}^{-1}$ at pretest to $48.7 \pm 9.2 \mathrm{~mL} \cdot \mathrm{min}^{-1} \cdot \mathrm{kg}^{-1}$ at posttest. No between-group differences were observed in work economy, and level of insomnia (ISI) or anxiety and depression (HAD), but a significant within-group improvement in depression was apparent for the TG. High intensity training was feasible for SUD patients in treatment. This training form should be implemented as a part of the rehabilitation since it, in contrast to the conventional treatment, represents a risk reduction for cardiovascular disease and premature death.
\end{abstract}

\section{Introduction}

Patients with substance use disorder (SUD), classified within ICD-10: F10-19 (mental and behavioral disorders due to psychoactive substance use) at the World Health Organization's mental and behavioral disorders classification, have a high prevalence of health and psychosocial problems in addition to their substance use disorder [1]. Although this patient group's disorder indeed has multifactorial causes, the evidence of how their physical capacity may be related to their calamitous lifestyle is sparse. Contributing to a decreased life expectancy of 15-20 years, the lowest among patients with different mental illnesses $[2,3]$ is an increased prevalence of cardiovascular disease [4-6]. The high risk of developing cardiovascular disease is associated with the population's drug use, poor nutrition, and obesity but is also likely a direct result of the patient group's inactivity [3].
Endurance training, especially with emphasis on high intensity, is shown to increase aerobic power and reduce the risk of cardiovascular disease [7-10]. Improvements of $10-30 \%$ in maximal oxygen consumption $\left(\mathrm{VO}_{2 \max }\right)$ have typically been observed in these studies, after training interventions of 2-3 months. These improvements may also be associated with large reductions in the risk of mortality, as an improvement of 1MET $\left(\sim 3.5 \mathrm{~mL} \cdot \mathrm{min}^{-1} \cdot \mathrm{kg}^{-1}\right)$ is shown to reduce the mortality rate by $12 \%$ [11]. Adding to the physical benefits of exercise are also possible effects on mental health. Although little is known about the effects of high-intensity interval training in SUD patients, exercise has been documented to have an overall beneficial effect on mental health and quality of life in patients with mental illnesses [12].

Despite the well-documented effect on cardiovascular disease risk reduction $[7,8,10]$, decreased mortality rate $[11,13,14]$, and improved mental health [15-19], effective 


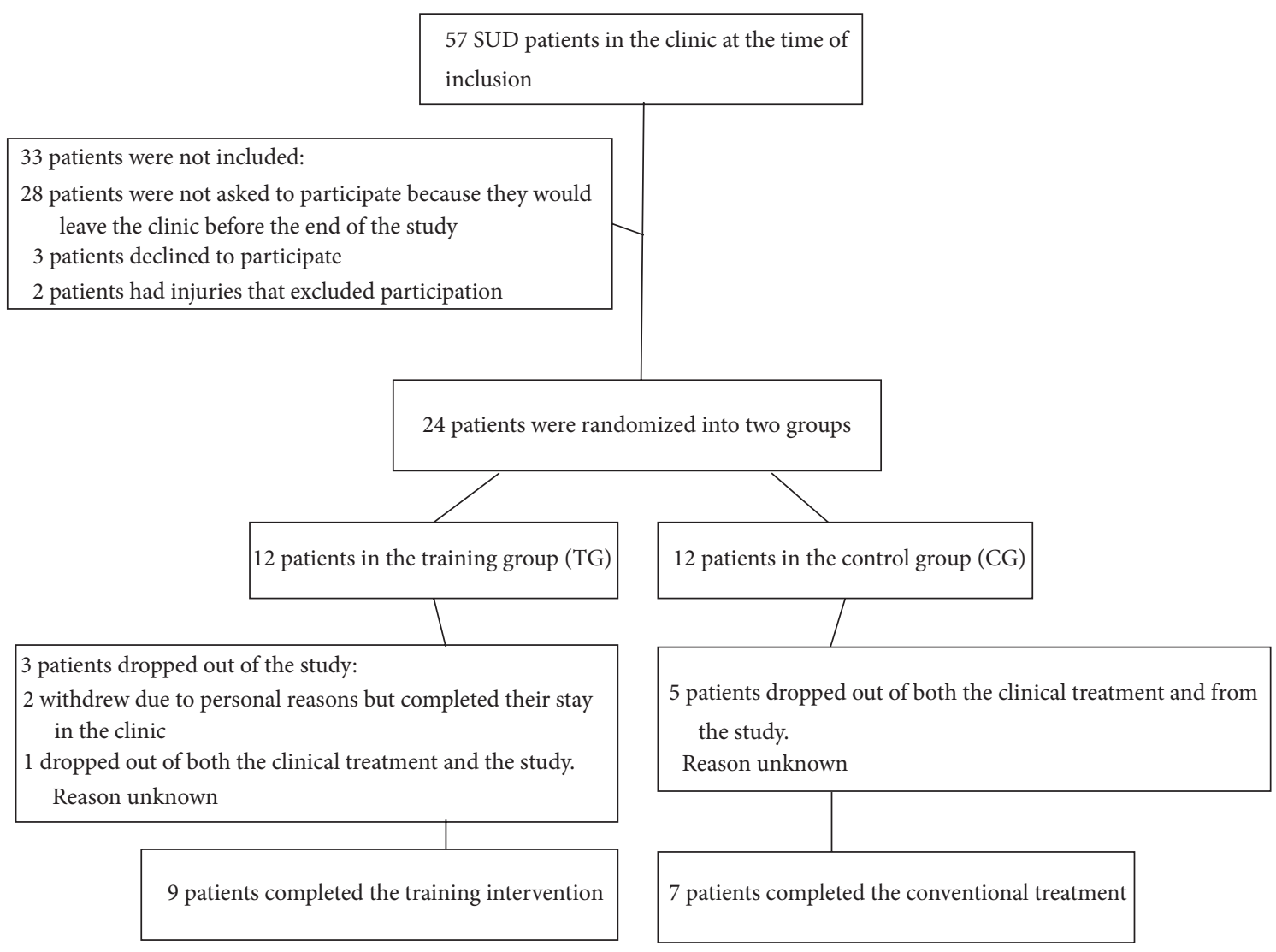

FIGURE 1: Recruitment, randomization, and withdrawal of SUD patients throughout the study.

physical training appears not to be a part of the conventional treatment for SUD patients. There has certainly been physical activities in the clinics for more than 30 years [20], but in general this activity seems random and unstructured and the frequency and intensity of the activities are often unknown. Indeed the activities may vary between clinics, but to our knowledge, it has not been documented that whole body exercise with a high intensity $\left(\geq 85 \%\right.$ of $\left.\mathrm{HR}_{\max }\right)$ constitutes a part of the clinical program. As physiological parameters rarely are documented, knowledge of physical status or improvements remains uncertain. Therefore, the aim of the present study was to examine if high-intensity interval training was feasible for SUD patients in treatment. Further, we aimed to document their aerobic power and compare the training group, if they were able to adhere, with patients receiving conventional treatment in the same clinic. Our hypotheses were that SUD patients (1) are able to complete a high-intensity interval training program, (2) have a decreased aerobic power at baseline compared to the average population, and (3) improve their $\mathrm{VO}_{2 \text { max }}$ and work economy more than the control group receiving conventional rehabilitation.

\section{Methods}

2.1. Subjects. 24 patients with a diagnosis of substance use disorder, ICD-10: F10-F19, were included in this study. All subjects participated in residential long term treatment in a substance abuse treatment clinic at the time of the study, due to abuse of illegal drugs. The long term treatment program at the clinic lasts for $\sim 3$ months. Subjects were excluded if they had been abstinent or/and systematically participated in endurance training for the last six months. Subjects were also excluded if they had cardiovascular disease or chronic obstructive pulmonary disease or were not able to perform treadmill testing and training. After signing the written informed consent, patients were randomized to either a high intensity training group (TG) or a conventional rehabilitation control group (CG) (Figure 1). Patient characteristics and medical use are given in Table 1 . The regional ethical committee did approve the study, and it was carried out in accordance with the Declaration of Helsinki.

\subsection{Testing}

2.2.1. Maximal Oxygen Consumption and Work Economy. Measurements of $\mathrm{VO}_{2 \max }$, work economy, and ventilatory parameters were obtained using the Cortex Metamax II portable metabolic test system (Cortex Biophysik $\mathrm{GmbH}$, Leipzig, Germany), walking/running on a treadmill (Woodway Weil am Rhein, Germany). After a 10-minute warm-up period, the subjects walked at $4.5 \mathrm{~km} \cdot \mathrm{h}^{-1}$ at $5 \%$ inclination for a period of 5 minutes. The average oxygen consumption for the last minute of this period was recorded as the work economy. Immediately following the work economy test, the 
TABLE 1: Patient characteristics and medical use.

\begin{tabular}{|c|c|c|c|}
\hline & $\begin{array}{c}\mathrm{TG} \\
(n=9)\end{array}$ & $\begin{array}{c}\mathrm{CG} \\
(n=7)\end{array}$ & $\begin{array}{c}\text { Combined } \\
(n=16)\end{array}$ \\
\hline Men/women $(n)$ & $8 / 1$ & $5 / 2$ & $13 / 3$ \\
\hline Age $(y r)$ & $33 \pm 11$ & $31 \pm 8$ & $32 \pm 9$ \\
\hline Height $(\mathrm{cm})$ & $177 \pm 10$ & $175 \pm 10$ & $176 \pm 10$ \\
\hline Weight (kg) & $84.1 \pm 14.9$ & $87.9 \pm 20.8$ & $85.8 \pm 17.2$ \\
\hline Current smoker & 8 & 6 & 14 \\
\hline Drug use debut (age) & $15 \pm 6$ & $17 \pm 4$ & $16 \pm 5$ \\
\hline Duration of abuse (yr) & $17 \pm 8$ & $12 \pm 4$ & $15 \pm 7$ \\
\hline \multicolumn{4}{|l|}{ Primary drug } \\
\hline Heroin & 1 & 1 & 2 \\
\hline BZD, Sed, Hypn & 1 & 1 & 2 \\
\hline Amphetamine & 4 & 4 & 8 \\
\hline Cannabis & 3 & 1 & 4 \\
\hline \multicolumn{4}{|l|}{ Secondary drug } \\
\hline Alcohol & 2 & 0 & 2 \\
\hline Heroin & 1 & 1 & 2 \\
\hline Opiates, painkillers & 2 & 1 & 3 \\
\hline Amphetamine & 1 & 0 & 1 \\
\hline Cannabis & 3 & 5 & 8 \\
\hline \multicolumn{4}{|l|}{$\begin{array}{l}\text { Symptoms for medicine } \\
\text { prescription: }\end{array}$} \\
\hline ADHD & 0 & 1 & 1 \\
\hline Allergies & 1 & 2 & 3 \\
\hline Anxiety & 2 & 1 & 3 \\
\hline Arthritis & 0 & 1 & 1 \\
\hline Asthma/COPD & 0 & 1 & 1 \\
\hline Depression & 1 & 2 & 3 \\
\hline Epilepsy & 0 & 1 & 1 \\
\hline Hypertension & 3 & 1 & 4 \\
\hline Schizophrenia/bipolar & 1 & 2 & 3 \\
\hline Substitutional treatment & 1 & 1 & 2 \\
\hline Other & 0 & 3 & 3 \\
\hline
\end{tabular}

Data are presented as mean \pm SD; TG: training group; CG: control group, Type of medication is reported on indication of symptoms according to common directory. The prescribed medicines in substitutional treatment are methadone and suboxone. Others: skin disorder, pain, and inflammation.

subjects continued to the $\mathrm{VO}_{2 \max }$ test. The incline was kept at $5 \%$ while velocity was increased by $1 \mathrm{~km} \cdot \mathrm{h}^{-1}$ every minute until exhaustion. $\mathrm{VO}_{2 \max }$, respiratory exchange ratio (RER) and ventilation were calculated averaging the three highest continuous 10 second values. One or more of the following criteria for reaching $\mathrm{VO}_{2 \max }$ were considered [21]: (1) if the oxygen consumption reached a plateau despite further increases in workload, (2) a RER above 1.05, and (3) lactate concentration in blood $\left(\left[\mathrm{La}^{-}\right]_{\mathrm{b}}\right)>7 \mathrm{mmol}$. Maximal heart rate $\left(\mathrm{HR}_{\max }\right)$ was calculated as 4 beats $\cdot \mathrm{min}^{-1}$ added to the highest heart rate during the last minute [22]. For heart rate assessment Polar F6 heart rate monitors were used (Polar Electro, Finland). $\left[\mathrm{La}^{-}\right]_{\mathrm{b}}$ were measured using the Biosen C_line (EKF Diagnostics GmbH, Barleben, Germany) analyzer. Blood from the patient's fingertip was sampled for analysis of blood lactate within $1 \mathrm{~min}$ after the $\mathrm{VO}_{2 \max }$ test. As an expression of maximal aerobic power, inclination and velocity at $\mathrm{VO}_{2 \max }$ were registered.

2.2.2. Identification of Drug Use. For identification of the extent of drug use the first page of EuropASI was applied (Addiction Severity Index, European adaption of The American 5th edition [23]). This index quantifies which substances have been used, when the patients started their use, and for how long the dependency has lasted. Further, the medical use for the patients participating in the study is given in Table 1 .

2.2.3. Insomnia, Anxiety, and Depression Questionnaires. In addition to the physical testing two questionnaires were implemented; Insomnia Severity Index (ISI) to detect possible cases of insomnia and Hospital Anxiety and Depression Scale (HAD) which is used to estimate the levels of anxiety and depression. These self-report questionnaires were answered before and after the training intervention as measures of psychological changes during the period of the study. The ISI has been evaluated to be a clinically useful tool for screening and quantifying perceived insomnia severity [24]. It is composed of 7 items targeting different categories of sleep disturbance severity. The items are rated at a five-point Likert scale (0-4) summed up to a total score ranging from 0 to 28 , where a higher score indicates more severe insomnia. The score categories are 0-7 (no clinically significant insomnia), 8-14 (subthreshold insomnia), 15-21 (clinical insomnia, moderate severity), and 22-28 (clinical insomnia, severe). The HAD self-assessment scale is consisting of a fourteen item scale, seven items related to anxiety and seven related to depression. On the subscales for anxiety and depression a score of $0-7$ for either subscale is estimated within the normal range, while a score of 11 or higher implies a probable presence of a mood disorder. A score of $8-10$ is considered signs of a mood disorder [25].

2.3. Training Intervention. Both the TG and the CG participated in the clinic treatment activities throughout the 8 -week intervention period. These activities included: Ballgames (indoor-soccer and volleyball), yoga, stretching, outdoor walking, low resistance strength training, ceramics, TV games, and card games. Additionally,the TG received supervised training 3 times a week for a period of 8 weeks. The training was performed as inclined walking or running on a treadmill, using the same heart rate monitor as during the $\mathrm{VO}_{2 \max }$ testing, to ensure correct intensity of every training session. The training sessions were organized as interval training, with $4 \times 4$ minutes of high aerobic intensity (90$95 \%$ of $\mathrm{HR}_{\max }$ ), interrupted by 3 -minute recovery periods $\left(\sim 70 \%\right.$ of $\left.\mathrm{HR}_{\max }\right)[21]$. All training sessions were supervised. As the subjects improved, velocity and incline were increased to meet the targeted heart rate. The subjects needed to have an adherence of at least 20 out of 24 training sessions in order to be included in the data analyses. Within the same time period as the TG performed their high-intensity interval training on a treadmill, the patients in the CG chose to participate 
TABLE 2: Changes in physiological parameters from pre- to posttest.

\begin{tabular}{lcccc}
\hline & & $\mathrm{TG}(N=9)$ & & $\mathrm{CG}(N=7)$ \\
& Pre & Post & Pre & \\
\hline $\mathrm{VO}_{2 \max }$ & & & $3.43 \pm 0.66$ & \\
$\quad\left(\mathrm{~L} \cdot \mathrm{min}^{-1}\right)$ & $3.60 \pm 0.91$ & $4.15 \pm 1.03^{* * \#}$ & $41.8 \pm 12.3$ & $3.54 \pm 0.65$ \\
$\quad\left(\mathrm{~mL} \cdot \mathrm{kg}^{-1} \cdot \mathrm{min}^{-1}\right)$ & $42.3 \pm 7.2$ & $48.7 \pm 9.2^{* * \#}$ & $103.5 \pm 24.4$ & $42.6 \pm 12.1$ \\
$V_{E}\left(\mathrm{~L} \cdot \mathrm{min}^{-1}\right)$ & $109.2 \pm 28.6$ & $125.9 \pm 36.8^{* * \#}$ & $1.17 \pm 0.11$ & $103.2 \pm 23.9$ \\
$\mathrm{RER}$ & $1.09 \pm 0.03$ & $1.10 \pm 0.02$ & $189 \pm 7$ & $1.14 \pm 0.06$ \\
$\mathrm{HR}_{\max }\left(\right.$ beats $\left.\cdot \mathrm{min}^{-1}\right)$ & $180 \pm 11$ & $181 \pm 14$ & $8.04 \pm 3.54$ & $188 \pm 7$ \\
{$\left[\mathrm{La}^{-}\right]_{\mathrm{b}}$} & $9.12 \pm 2.41$ & $10.65 \pm 1.69$ & $9.21 \pm 2.01$ \\
\hline
\end{tabular}

Data are presented as mean $\pm \mathrm{SD}$. TG: training group; CG: control group; $\mathrm{VO}_{2 \max }$ : maximal oxygen uptake; $V_{E}$ : ventilation; RER: respiratory exchange ratio; $\mathrm{HR}_{\max }$ : maximal heart rate; $\left[\mathrm{La}^{-}\right]_{\mathrm{b}}$ : lactate concentration in blood, ${ }^{* *} P<0.01$, difference within group from pre- to posttest, ${ }^{\#} P<0.05$, differences in changes from pre- to posttest between groups.

in a self-elected activity among the offered sports or games in the clinical treatment program. Although representing a wide range of different activities, they all shared a measured or estimated intensity level of $<70 \%$ of $\mathrm{HR}_{\max }$.

2.4. Statistics. Statistical analyses were performed using the software SPSS, version 20 (Chicago, USA), and figures were made using the software GraphPad Prism 5 (San Diego, USA). Relative improvements are given as mean percentage change. To determine if the data was normal distributed a QQ plot was used. Repeated measures ANOVAs (2 (group) $\times 2$ training status) were used to determine differences between groups following training. If appropriate, a Tukey post hoc analysis was used. Unpaired and paired $t$-tests were used to detect differences between groups at baseline and within group following training, respectively. Statistical significance was accepted at an $\alpha$-level of $P<0.05$. Data are reported as mean $\pm \mathrm{SD}$, unless otherwise noted. Additionally, using similar statistics, an intention to treat analysis with the use of last observation carried forward for missing data was carried out for all the 24 subjects that were randomized to the two groups. To achieve a statistical power of $80 \%, 8$ patients in each group needed to complete the study period in order to observe a $0.375 \mathrm{~L} \cdot \mathrm{min}^{-1}$ improvement difference in mean $\mathrm{VO}_{2 \text { max }}$ between $\mathrm{TG}$ and $\mathrm{CG}$, assuming a $\mathrm{SD}$ of $0.25 \mathrm{~L} \cdot \mathrm{min}^{-1}$. These values were based on previous studies from our group using the same training intervention in other populations. The drop-out rate in previous studies has been $\sim 2 / 10$ subjects. However, considering that this patient population may be more challenging than average, a higher drop-out rate is expected. Thus 12 subjects were randomized to each group to ensure observation of the assumed efficacy difference between the two groups.

\section{Results}

11 of the 12 SUD patients in the TG and 7 out of 12 patients in the CG, respectively, completed their overall intended stay at the substance use disorder clinic. With regard to the high intensity training, 3 subjects withdrew from the TG. Two withdrew due to personal reasons but remained in the clinical treatment, while one dropped out from both the clinical treatment and the TG. In the CG 5 subjects dropped out of the clinical treatment and thus withdrew from the study without giving any reasons (Figure 1). The SUD patients that completed the training period carried out $22 \pm 1$ of the scheduled supervised training sessions. The targeted intensity (90$95 \%$ of $\mathrm{HR}_{\max }$ ) was reached in all completed sessions. None of the subjects reported any problems or discomfort completing the training sessions, other than the normal strain following high intensity exercise.

At baseline, before the withdrawal of subjects from the study, values for both groups combined were $44 \pm 8$ (males) and $34 \pm 9$ (females) $\mathrm{mL} \cdot \mathrm{min}^{-1} \cdot \mathrm{kg}^{-1}$, respectively. $\mathrm{VO}_{2 \max }$ significantly $(P<0.01)$ improved by $15 \pm 7 \%$ for the 9 subjects that completed the TG (Table 2). This improvement was also significantly $(P<0.01)$ different from the CG (Figure 2$)$. In accordance with the improvement in aerobic power, the TG also increased velocity and inclination at $\mathrm{VO}_{2 \max }$ from $9.2 \pm$ $2.3 \mathrm{~km} \cdot \mathrm{h}^{-1}$ and $5.6 \pm 1.1 \%$ at pretest to $9.3 \pm 2.2 \mathrm{~km} \cdot \mathrm{h}^{-1}$ and $8.3 \pm 2.4 \%$ at posttest. The CG showed no within-group improvement in neither $\mathrm{VO}_{2 \max }$ nor maximal workload. The TG increased ventilation at $\mathrm{VO}_{2 \text { max }}$ by $14 \pm 10 \%$, while there were no differences within or between groups in RER or $\left[\mathrm{La}^{-}\right]_{\mathrm{b}}$ at $\mathrm{VO}_{2 \text { max }}$ from pre- to posttest. An intention to treat analysis, including all 24 participants that were randomized to either the TG or the CG, did not show different results for the primary outcomes compared to analysis including only subjects that completed the study.

Work economy, measured at $5 \%$ inclination and $4.5 \mathrm{~km}$. $\mathrm{h}^{-1}$ on the treadmill, showed no significant differences between or within the two groups following the training period (Table 3). However, the heart rate at the work economy workload significantly $(P<0.05)$ decreased by $9 \pm 12 \%$ in the TG, but this within-group change was only apparent as a trend $(P=0.158)$ when compared to the CG.

For psychological variables, the TG displayed a significant $(P<0.05)$ decrease in depression level following the training period, whereas the CG had a significant decrease $(P<0.05)$ in anxiety level from pre- to posttest (Table 4). However, neither of these within-group differences, measured by the Hospital Anxiety and Depression questionnaire, was apparent as between-group differences. 


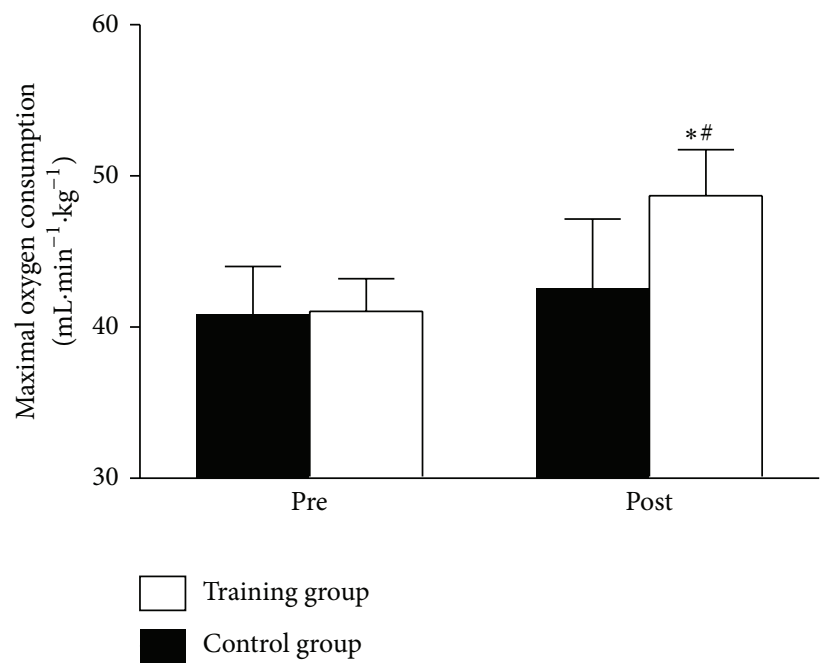

Figure 2: Maximal oxygen consumption before and after the training intervention. Data are presented as mean \pm SE. ${ }^{*} P<0.01$, difference within group from pre- to posttest, ${ }^{\#} P<0.05$, differences in changes from pre- to posttest between groups.

TABLE 3: Work economy measured at $4.5 \mathrm{~km} \cdot \mathrm{h}^{-1}$ and $5 \%$ inclination at pre- and posttest.

\begin{tabular}{lcccc}
\hline & & $\mathrm{TG}(\mathrm{N}=9)$ & & $\mathrm{CG}(N=7)$ \\
& Pre & Post & Pre & \\
\hline $\mathrm{VO}_{2}$ & & & & \\
$\quad\left(\mathrm{~L} \cdot \mathrm{min}^{-1}\right)$ & $1.54 \pm 0.24$ & $1.61 \pm 0.28$ & $1.70 \pm 0.36$ & $1.77 \pm 0.43$ \\
$\quad\left(\mathrm{ML} \cdot \mathrm{kg}^{-1} \cdot \mathrm{min}^{-1}\right)$ & $18.5 \pm 1.1$ & $18.9 \pm 1.3$ & $19.6 \pm 2.3$ & $20.2 \pm 1.4$ \\
$V_{E}\left(\mathrm{~L} \cdot \mathrm{min}^{-1}\right)$ & $35.1 \pm 4.4$ & $33.3 \pm 5.3$ & $38.3 \pm 9.3$ & $41.1 \pm 9.0$ \\
$\mathrm{RER}$ & $0.90 \pm 0.04$ & $0.89 \pm 0.08$ & $0.93 \pm 0.05$ & $0.94 \pm 0.07$ \\
$\mathrm{HR}_{\max }\left(\right.$ beats $\left.\cdot \mathrm{min}^{-1}\right)$ & $116 \pm 17$ & $105 \pm 18$ & $116 \pm 18$ & $119 \pm 9$ \\
\hline
\end{tabular}

Data are presented as mean $\pm \mathrm{SD}$. TG: training group; CG: control group; $\mathrm{VO}_{2}$ : oxygen uptake; $V_{E}$ : ventilation; RER: respiratory exchange ratio; $\mathrm{HR}$ max maximal heart rate.

TABLE 4: Psychological changes from pre- to posttest (scores from the insomnia severity index and hospital anxiety and depression scale questionnaires).

\begin{tabular}{lcccc}
\hline & \multicolumn{2}{c}{ TG $(n=9)$} & \multicolumn{2}{c}{ CG $(n=7)$} \\
& Pre & Post & Pre & Post \\
\hline Anxiety & $9.4 \pm 3.5$ & $8.6 \pm 2.5$ & $9.1 \pm 5.3$ & $6.3 \pm 3.4^{*}$ \\
Depression & $8.5 \pm 4.8$ & $5.3 \pm 3.9^{*}$ & $6.0 \pm 3.5$ & $4.6 \pm 3.5$ \\
Insomnia & $10.6 \pm 5.4$ & $8.9 \pm 5.1$ & $10.9 \pm 10.1$ & $9.1 \pm 5.0$ \\
\hline
\end{tabular}

Data are presented as means \pm SD. TG: training group; CG: control group. ${ }^{*} P<0.05$, difference within group from pre- to posttest.

\section{Discussion}

Since little is known about the aerobic power of SUD patients in treatment and their lifestyle indicates that they may suffer a high risk of cardiovascular and lifestyle diseases, this study sought to investigate the aerobic power of this group of patients and their response to exercise training of high intensity. The main findings of the study were as follows (1) the initial aerobic power at baseline is lower than what is typically seen in the average population, (2) the SUD patients improved their aerobic power and work performance following the training intervention, thus decreasing the risk factors for lifestyle diseases, and (3) the training intervention is applicable as a part of the clinical treatment.

4.1. Reduced Aerobic Power in Patients with Substance Use Disorder. At inclusion, the SUD patients in the present study had a baseline $\mathrm{VO}_{2 \max }$ of $44 \pm 8$ (males) and $34 \pm 9$ (females) $\mathrm{mL} \cdot \mathrm{min}^{-1} \cdot \mathrm{kg}^{-1}$. This is well below age-matched reference data from the average population [26]. The $10 \%$ and $16 \%$ lower baselines for the $\sim 30$ year old males and females, respectively, are comparable to the average values observed among 5059-year-old healthy subjects [26]. The low aerobic power, as documented in the current study, is in line with a previous study displaying $\mathrm{VO}_{2 \max }$ values of 39 (males) and $31 \mathrm{~mL}$. $\mathrm{min}^{-1} \cdot \mathrm{kg}^{-1}$ (females) in SUD patients [27]. Our study and the Mamen and Martinsen [27] study are to our knowledge the only studies to directly assess aerobic power in SUD patients. However, the assumption of a health-related critical low aerobic power is also supported by several studies applying estimations of $\mathrm{VO}_{2 \max }[17,28-31]$. Since low aerobic power is a well-established risk factor for cardiovascular disease and all-cause mortality $[11,13,14,32]$, it is likely that the low $\mathrm{VO}_{2 \text { max }}$ observed among SUD patients may, at least in part, be responsible for the elevated prevalence of cardiovascular disease and premature death observed in this patient group. 
It is therefore surprising that aerobic power commonly is not listed as one of the major causes for illnesses, medical conditions, and early death in SUD patients $[3,4,6]$.

4.2. Exercise-Induced Effect on Aerobic Power, Work Load, and Risk Reduction. As expected, the SUD patients that completed the supervised eight week treadmill training period in the current study improved $\mathrm{VO}_{2 \max }$. In accordance with the $15 \pm 7 \%$ improvement in $\mathrm{VO}_{2 \max }$, the $\mathrm{TG}$ increased maximal velocity and inclination at $\mathrm{VO}_{2 \max }$ from $9.2 \pm 2.3 \mathrm{~km} \cdot \mathrm{h}^{-1}$ and $5.6 \pm 1.1 \%$ at pretest to $9.3 \pm 2.2 \mathrm{~km} \cdot \mathrm{h}^{-1}$ and $8.3 \pm 2.4 \%$ at posttest. For patient groups with low aerobic capacities, daily activities are often perceived as strenuous. An improvement in work capacity is therefore typically associated with an increased wellbeing in everyday life, since it reduces the relative intensity on the daily tasks [10, 33, 34]. The improvement in $\mathrm{VO}_{2 \max }$ observed in our study is similar to what have previously been reported following a whole body high intensity $\left(>85 \%\right.$ of $\mathrm{HR}_{\max }$ ) training intervention in a wide range of patient groups $[7-10,35,36]$, as well as and in healthy subjects [21, 37] and old subjects [37]. The magnitude of $\mathrm{VO}_{2} \max$ improvement may be influenced by training status, age, or pathology [710]. Subjects with a low baseline are, both mathematically and physiologically, susceptible to larger percentage improvements $(\sim 15-35 \%)$ than subjects with a higher baseline $(\sim 6 \%-13 \%)[21,37]$.

Considering the elevated risk of mortality [3] and cardiovascular incidents in SUD patients [4], $\mathrm{VO}_{2 \max }$ improvements as demonstrated in the present study are beneficial. A $3.5 \mathrm{~mL} \cdot \mathrm{min}^{-1} \cdot \mathrm{kg}^{-1}$ improvement in $\mathrm{VO}_{2 \max }$ has been shown to be associated with a $12 \%$ improved chance of survival [11] and a 15\% reduced risk for developing cardiovascular disease [32]. The SUD patients in the present study improved their $\mathrm{VO}_{2 \max }$ by $6.6 \mathrm{~mL} \cdot \mathrm{min}^{-1} \cdot \mathrm{kg}^{-1}$, indicating that not only will they have a strongly decreased mortality rate, but also a considerable reduced risk of developing cardiovascular disease. After the relatively short-duration training period the SUD patients restored their $\mathrm{VO}_{2 \text { max }}$ values to a level similar to the age-matched healthy population [26]. In contrast, it is thought provoking that conventional clinical treatment did not improve $\mathrm{VO}_{2 \text { max }}$. Physical activity is certainly applied in today's treatment [20], but clearly this physical activity is not sufficient to induce improvements in $\mathrm{VO}_{2 \max }$. Since the conventional activities are all reported to be carried out with a low intensity, this may explain the lack of improvement, as intensity is suggested to be the key factor for $\mathrm{VO}_{2 \max }$ improvements $[21,38]$. Recognizing the high risk for cardiovascular disease and mortality in these patients, it is critical that today's treatment may have no effect on one of the most important factors for these conditions.

The exercise-induced improvement in $\mathrm{VO}_{2 \max }$ that was observed in the TG is likely due to an improvement in maximal cardiac output, and more specific is the stroke volume of the heart since no changes were observed in $\mathrm{HR}_{\max }$. Previously the stroke volume has been shown to be the decisive factor that explains the adaptations to high intensity training, both in moderately trained healthy subjects [21] and in untrained coronary artery disease patients [39]. The $\sim 42 \mathrm{~mL} \cdot \mathrm{min}^{-1} \cdot \mathrm{kg}^{-1}$ (males and females combined) baseline $\mathrm{VO}_{2 \text { max }}$ in the current study falls between an aerobic power of $\sim 55$ (young, healthy) and $\sim 27$ (coronary artery disease) $\mathrm{mL}$. $\min ^{-1} \cdot \mathrm{kg}^{-1}$. Although the SUD patients indeed represent a different group of subjects, it is likely, since the stroke volume adaptations appear to be similar across different populations, that also their improvements in $\mathrm{VO}_{2 \max }$ originate from training-induced changes in maximal stroke volume.

4.3. Training Effect on Insomnia, Anxiety, and Depression. A positive relationship between exercise and mood disorders is well-documented $[20,40-44]$ specifically apparent as insomnia [40, 45], anxiety [44], and depression disorder $[41,43,46]$ reductions. Therefore, it is surprising that the large difference between the TG and the CG in aerobic power and work load following the study period did not induce detectable differences between groups in any of these variables. At baseline, the level of mental distress in both the TG and the CG group was ranged as moderately severe according to the Insomnia Severity Index and the Hospital Anxiety and Depression Scale. Both groups scored within subthreshold for insomnia and within signs of mood disorder. Following the study period there was a reduction of the depression variable within the TG, as well as a reduction of the anxiety variable within the $C G$, but these reductions were not different between the two groups. It is possible that psychological benefits, as measured by the questionnaires in our study, are more related to physical activity per se and not necessarily to aerobic exercise training. Although reduced depression symptoms may be associated with exercise in general and not necessarily restricted to the aerobic form of exercise [15], it should undoubtedly be expected that a risk reduction of cardiovascular disease and mortality would cause an improvement of mood disorders and quality of life [42]. Thus the commonly applied questionnaires that were used in our study should be able to detect such an improvement. Our results indicate that a supplement, expansion, or replacement to/of the questionnaires are sought for, although it is recognized that the relatively small sample size in the current study may be, in part, responsible for the nondetectable differences in mood disorders.

4.4. High-Intensity Interval Training: Clinical Implications. Considering their high rate of nonattendance and discontinuation $[47,48]$, reflected in the high relapse rates from clinical treatment [49], an important question in the current study was whether the SUD patients were able to carry out the scheduled period of training. To our knowledge there have not been any previous reports of SUD patients participating in such an intensive training intervention. The SUD patients were in our study capable of managing the intensive training, reflected in the high attendance $(22 \pm 1$ of the total 24 scheduled training sessions) for the 9 subjects that completed the training period. Interestingly, the completion rate was higher for the TG, both in the current study and in the clinical treatment, compared to the CG. Only 1 out of 12 patients in the TG dropped out from clinical treatment $(5$ subjects in the CG) and 3 from the training study (5 subjects in the 
CG). Certainly these withdrawals could be due to chance, but the completion rate is nevertheless a testament to the feasibility of high-intensity interval training as part of the clinical treatment. An intention to treat analysis showed no differences in the main findings of the current study and thus strengthens the result of an overall beneficial effectiveness of high-intensity interval training in a clinical setting. Not only was it feasible to apply this intervention in the clinic, but additionally the subjects that completed the training reported no discomfort or pain during the training sessions other than what should be expected with high intensity training, and not one single commenced training session was aborted.

Our findings are in line with a previous study applying a similar training intervention in patients with schizophrenia [10]. In the Heggelund et al. study [10] the training was reported to be challenging but feasible. In our study, as well as in the Heggelund et al. study [10], all trainings were conducted in presence of a supervisor. This may be favorable when implementing a training intervention in mentally ill patients. Mamen et al. [50] emphasized that the relationship between the patient and the supervisor can prove essential for the patients motivation and commitment to the project. Our experience throughout this study supports this notion. The present study exemplifies that high intensity training can be applicable for SUD patients in treatment and that the intensive training is manageable also for this patient group. Considering the health benefits associated with this training, it should be implemented as a complementary treatment for SUD patients.

\section{Conclusion}

In the present study SUD patients are shown to have a low aerobic power, and thus they are at risk for developing cardiovascular disease. As it is important that SUD patients receive both a physical and psychological treatments in the clinic and our results indicate that the conventional treatment is not sufficient to reduce the risk of cardiovascular disease, highintensity interval training should be implemented as part of the clinical treatment to effectively improve the patient groups' aerobic power.

\section{Conflict of Interests}

The authors declare that they have no conflict of interests regarding the publication of this paper.

\section{Acknowledgment}

This project was funded by the Liaison Committee between the Central Norway Regional Health Authority and the Norwegian University of Science and Technology.

\section{References}

[1] P. M. Flynn and B. S. Brown, "Co-occurring disorders in substance abuse treatment: issues and prospects," Journal of Substance Abuse Treatment, vol. 34, no. 1, pp. 36-47, 2008.
[2] F. Amaddeo, G. Bisoffi, P. Bonizzato, R. Micciolo, and M. Tansella, "Mortality among patients with psychiatric illness. A ten-year case register study in an area with a community-based system of care," British Journal of Psychiatry, vol. 166, pp. 783788, 1995.

[3] M. Nordentoft, K. Wahlbeck, J. Hallgren et al., "Excess mortality, causes of death and life expectancy in 270, 770 patients with recent onset of mental disorders in Denmark, Finland and Sweden," PLoS One, vol. 8, no. 1, Article ID e55176, 2013.

[4] E. C. Harris and B. Barraclough, "Excess mortality of mental disorder," British Journal of Psychiatry, vol. 173, pp. 11-53, 1998.

[5] S. Kaye, R. McKetin, J. Duflou, and S. Darke, "Methamphetamine and cardiovascular pathology: a review of the evidence," Addiction, vol. 102, no. 8, pp. 1204-1211, 2007.

[6] M. Stenbacka, A. Leifman, and A. Romelsjö, "Mortality and cause of death among 1705 illicit drug users: a 37 year follow up," Drug and Alcohol Review, vol. 29, no. 1, pp. 21-27, 2010.

[7] U. Wisløff, A. Støylen, J. P. Loennechen et al., "Superior cardiovascular effect of aerobic interval training versus moderate continuous training in heart failure patients: a randomized study," Circulation, vol. 115, no. 24, pp. 3086-3094, 2007.

[8] A. E. Tjønna, S. J. Lee, Ø. Rognmo et al., "Aerobic interval training versus continuous moderate exercise as a treatment for the metabolic syndrome: a pilot study," Circulation, vol. 118, no. 4, pp. 346-354, 2008.

[9] J. Helgerud, E. Wang, M. P. Mosti, Ø. N. Wiggen, and J. Hoff, "Plantar flexion training primes peripheral arterial disease patients for improvements in cardiac function," European Journal of Applied Physiology, vol. 106, no. 2, pp. 207-215, 2009.

[10] J. Heggelund, G. E. Nilsberg, J. Hoff, G. Morken, and J. Helgerud, "Effects of high aerobic intensity training in patients with schizophrenia: a controlled trial," Nordic Journal of Psychiatry, vol. 65 , no. 4, pp. 269-275, 2011.

[11] J. Myers, M. Prakash, V. Froelicher, D. Do, S. Partington, and J. Edwin Atwood, "Exercise capacity and mortality among men referred for exercise testing," The New England Journal of Medicine, vol. 346, no. 11, pp. 793-801, 2002.

[12] P. Gorczynski and G. Faulkner, "Exercise therapy for schizophrenia," Schizophrenia Bulletin, vol. 36, no. 4, pp. 665-666, 2010.

[13] M. Wei, J. B. Kampert, C. E. Barlow et al., "Relationship between low cardiorespiratory fitness and mortality in normal-weight, overweight, and obese men," Journal of the American Medical Association, vol. 282, no. 16, pp. 1547-1553, 1999.

[14] S. N. Blair, J. B. Kampert, H. W. Kohl III et al., "Influences of cardiorespiratory fitness and other precursors on cardiovascular disease and all-cause mortality in men and women," Journal of the American Medical Association, vol. 276, no. 3, pp. 205-210, 1996.

[15] E. W. Martinsen, A. Hoffart, and O. Solberg, "Comparing aerobic with nonaerobic forms of exercise in the treatment of clinical depression: a randomized trial," Comprehensive Psychiatry, vol. 30, no. 4, pp. 324-331, 1989.

[16] R. A. Brown, A. M. Abrantes, J. P. Read et al., "Aerobic exercise for alcohol recovery: rationale, program description, and preliminary findings," Behavior Modification, vol. 33, no. 2, pp. 220-249, 2009.

[17] T. R. Collingwood, R. Reynolds, H. W. Kohl, W. Smith, and S. Sloan, "Physical fitness effects on substance abuse risk factors and use patterns," Journal of Drug Education, vol. 21, no. 1, pp. 73-84, 1991. 
[18] J. Palmer, N. Vacc, and J. Epstein, "Adult inpatient alcoholics: physical exercise as a treatment intervention," Journal of Studies on Alcohol, vol. 49, no. 5, pp. 418-421, 1988.

[19] E. W. Martinsen, "Physical activity in the prevention and treatment of anxiety and depression," Nordic Journal of Psychiatry, vol. 62 , no. 47, pp. 25-29, 2008.

[20] A. Mamen and E. W. Martinsen, "Development of aerobic fitness of individuals with substance abuse/dependence following long-term individual physical activity," European Journal of Sport Science, vol. 10, no. 4, pp. 255-262, 2010.

[21] J. Helgerud, K. Høydal, E. Wang et al., "Aerobic high-intensity intervals improve $\mathrm{VO}_{2 \max }$ more than moderate training," Medicine \& Science in Sports \& Exercise, vol. 39, no. 4, pp. 665671, 2007.

[22] E. Wang, G. S. Solli, S. K. Nyberg, J. Hoff, and J. Helgerud, "Stroke volume does not plateau in female endurance athletes," International Journal of Sports Medicine, vol. 33, no. 9, pp. 734739, 2012.

[23] A. T. McLellan, H. Kushner, D. Metzger et al., "The fifth edition of the Addiction Severity Index," Journal of Substance Abuse Treatment, vol. 9, no. 3, pp. 199-213, 1992.

[24] C. H. Bastien, A. Vallières, and C. M. Morin, "Validation of the insomnia severity index as an outcome measure for insomnia research," Sleep Medicine, vol. 2, no. 4, pp. 297-307, 2001.

[25] H. Værøy, "Depression, anxiety, and history of substance abuse among Norwegian inmates in preventive detention: reasons to worry?" BMC Psychiatry, vol. 11, article 40, 2011.

[26] H. Loe, Ø. Rognmo, B. Saltin, and U. Wisløff, "Aerobic capacity reference data in 3816 healthy men and women 20-90 years," PLoS One, vol. 8, no. 5, Article ID e64319, 2013.

[27] A. Mamen and E. W. Martinsen, "The aerobic fitness of substance abusers voluntary participating in a rehabilitation project," Journal of Sports Medicine and Physical Fitness, vol. 49, no. 2, pp. 187-193, 2009.

[28] A. Frankel and J. Murphy, "Physical fitness and personality in alcoholism. Canonical analysis of measures before and after treatment," Quarterly Journal of Studies on Alcohol, vol. 35, no. 4, part A, pp. 1272-1278, 1974.

[29] D. Sinyor, T. Brown, L. Rostant, and P. Seraganian, "The role of a physical fitness program in the treatment of alcoholism," Journal of Studies on Alcohol, vol. 43, no. 3, pp. 380-386, 1982.

[30] E. H. Sell and N. J. Christensen, "The effect of physical training on physical, mental and social conditions in drug and/or alcohol addicts," Ugeskrift for Laeger, vol. 151, no. 33, pp. 2064-2067, 1989.

[31] K. K. Roessler, "Exercise treatment for drug abuse-a danish pilot study," Scandinavian Journal of Public Health, vol. 38, no. 6, pp. 664-669, 2010.

[32] S. Kodama, K. Saito, S. Tanaka et al., "Cardiorespiratory fitness as a quantitative predictor of all-cause mortality and cardiovascular events in healthy men and women: a meta-analysis," Journal of the American Medical Association, vol. 301, no. 19, pp. 2024-2035, 2009.

[33] J. G. Regensteiner, J. F. Steiner, and W. R. Hiatt, "Exercise training improves functional status in patients with peripheral arterial disease," Journal of Vascular Surgery, vol. 23, no. 1, pp. 104115, 1996.

[34] R. Willenheimer, L. Erhardt, C. Cline, E. Rydberg, and B. Israelsson, "Exercise training in heart failure improves quality of life and exercise capacity," European Heart Journal, vol. 19, no. 5, pp. 774-781, 1998.
[35] S. A. Slørdahl, E. Wang, J. Hoff, O. J. Kemi, B. H. Amundsen, and J. Helgerud, "Effective training for patients with intermittent claudication," Scandinavian Cardiovascular Journal, vol. 39, no. 4, pp. 244-249, 2005.

[36] J. Helgerud, T. Karlsen, W. Y. Kim et al., "Interval and strength training in CAD Patients," International Journal of Sports Medicine, vol. 32, no. 1, pp. 54-59, 2011.

[37] E. Wang, M. S. Næss, J. Hoff et al., "Exercise-training-induced changes in metabolic capacity with age: the role of central cardiovascular plasticity," Age, 2013.

[38] H. A. Wenger and G. J. Bell, “The interactions of intensity, frequency and duration of exercise training in altering cardiorespiratory fitness," Sports Medicine, vol. 3, no. 5, pp. 346-356, 1986.

[39] J. Helgerud, S. Bjørgen, T. Karlsen et al., "Hyperoxic interval training in chronic obstructive pulmonary disease patients with oxygen desaturation at peak exercise," Scandinavian Journal of Medicine and Science in Sports, vol. 20, no. 1, pp. el70-e176, 2010.

[40] S. D. Youngstedt, "Effects of exercise on sleep," Clinics in Sports Medicine, vol. 24, no. 2, pp. 355-365, 2005.

[41] E. W. Martinsen, A. Medhus, and L. Sandvik, "Effects of aerobic exercise on depression: a controlled study," British Medical Journal, vol. 291, no. 6488, p. 109, 1985.

[42] D. I. Galper, M. H. Trivedi, C. E. Barlow, A. L. Dunn, and J. B. Kampert, "Inverse association between physical inactivity and mental health in men and women," Medicine and Science in Sports and Exercise, vol. 38, no. 1, pp. 173-178, 2006.

[43] J. Mota-Pereira, J. Silverio, S. Carvalho, J. C. Ribeiro, D. Fonte, and J. Ramos, "Moderate exercise improves depression parameters in treatment-resistant patients with major depressive disorder," Journal of Psychiatric Research, vol. 45, no. 8, pp. 10051011, 2011.

[44] S. Saxena, M. Van Ommeren, K. C. Tang, and T. P. Armstrong, "Mental health benefits of physical activity," Journal of Mental Health, vol. 14, no. 5, pp. 445-451, 2005.

[45] G. S. Passos, D. L. Poyares, M. G. Santana, S. Tufik, and M. T. Mello, "Is exercise an alternative treatment for chronic insomnia?” Clinics, vol. 67, no. 6, pp. 653-660, 2012.

[46] A. L. Dunn, M. H. Trivedi, J. B. Kampert, C. G. Clark, and H. O. Chambliss, "Exercise treatment for depression: efficacy and dose response," American Journal of Preventive Medicine, vol. 28, no. 1, pp. 1-8, 2005.

[47] L. F. Sparr, M. C. Moffitt, and M. F. Ward, "Missed psychiatric appointments: who returns and who stays away," American Journal of Psychiatry, vol. 150, no. 5, pp. 801-805, 1993.

[48] H. R. Kranzler, R. Escobar, D.-K. Lee, and E. Meza, "Elevated rates of early discontinuation from pharmacotherapy trials in alcoholics and drug abusers," Alcoholism, vol. 20, no. 1, pp. 1620, 1996.

[49] S. A. Ball, K. M. Carroll, M. Canning-Ball, and B. J. Rounsaville, "Reasons for dropout from drug abuse treatment: symptoms, personality, and motivation," Addictive Behaviors, vol. 31, no. 2, pp. 320-330, 2006.

[50] A. Mamen, S. Pallesen, and E. W. Martinsen, "Changes in mental distress following individualized physical training in patients suffering from chemical dependence," European Journal of Sport Science, vol. 11, no. 4, pp. 269-276, 2011. 


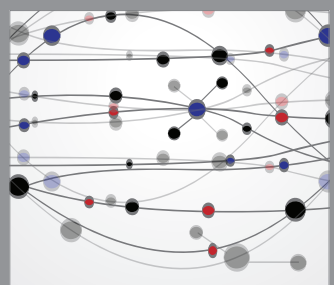

The Scientific World Journal
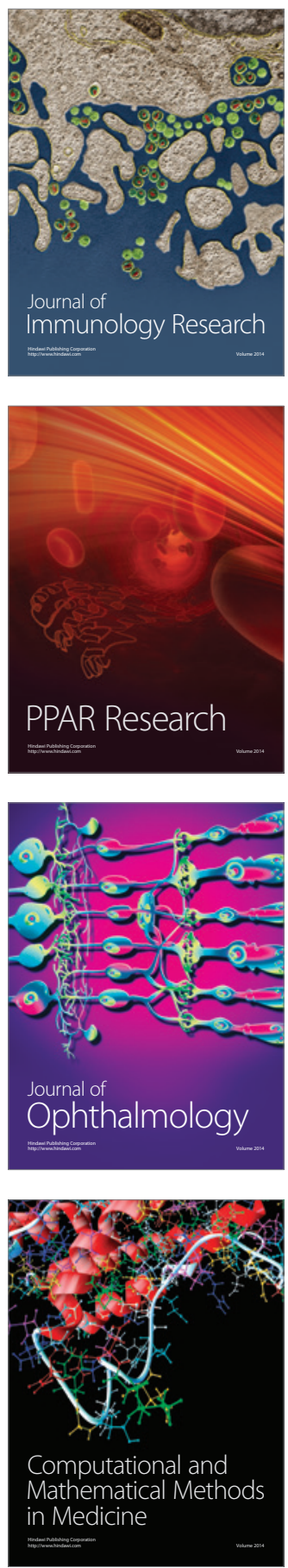

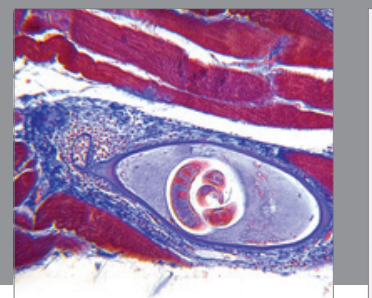

Gastroenterology

Research and Practice
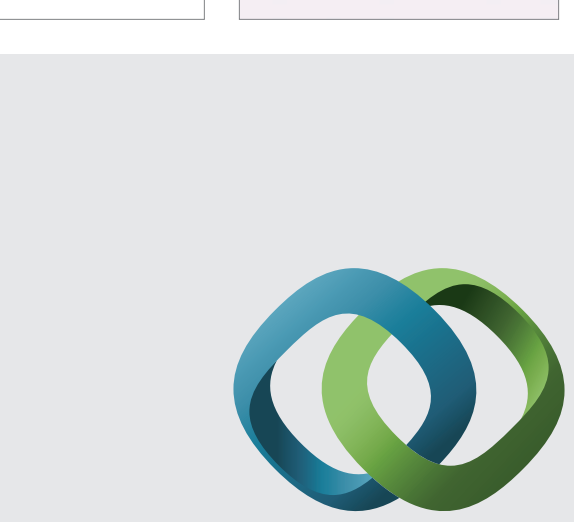

\section{Hindawi}

Submit your manuscripts at

http://www.hindawi.com
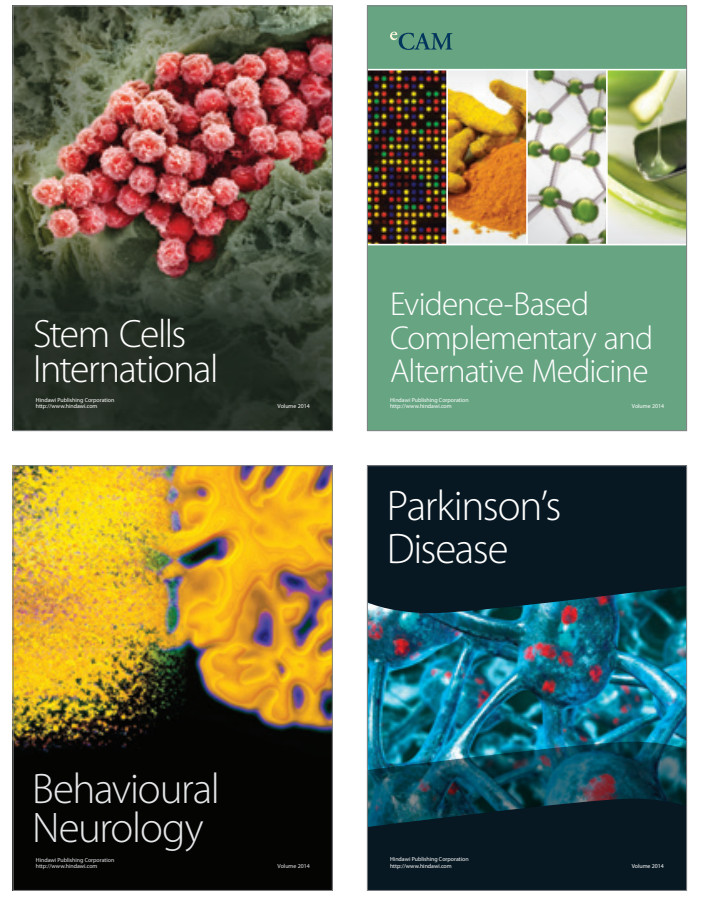
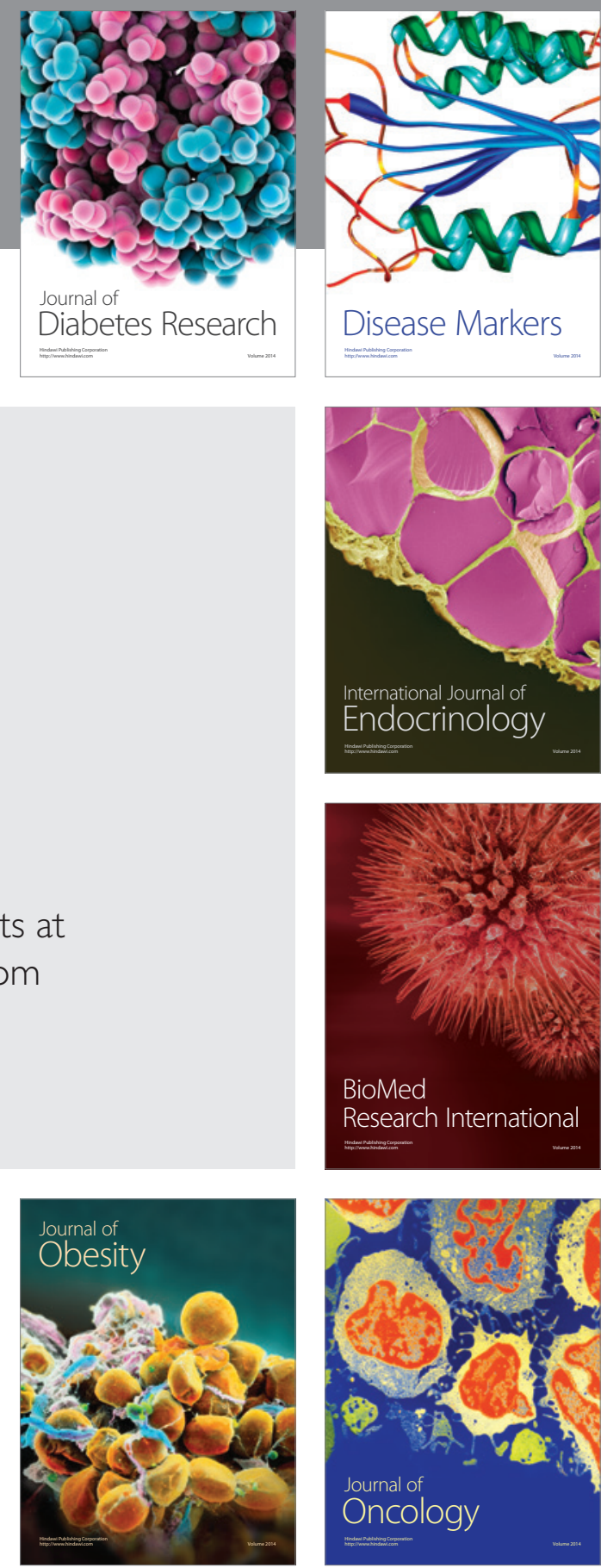

Disease Markers
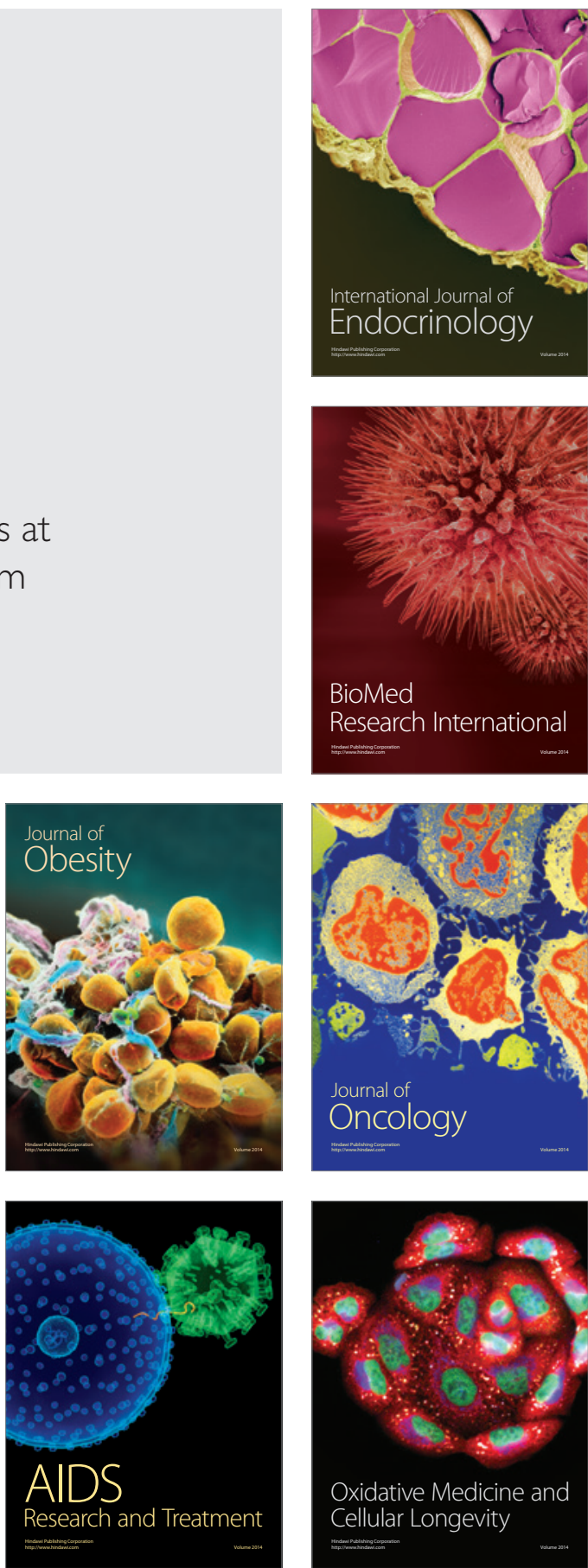